\title{
OS DESAFIOS ENFRENTADOS PELO PROFISSIONAL DE SECRETARIADO EXECUTIVO DO GÊNERO MASCULINO NAS ORGANIZAÇÕES CONTEMPORÂNEAS
}

\section{THE CHALLENGES FACED BY THE MALE GENDER EXECUTIVE SECRETARY} PROFESSIONAL IN CONTEMPORARY ORGANIZATIONS

\section{Conceição de Maria Pinheiro Barros}

Mestre em Políticas Públicas e Gestão da Educação Superior, pela Universidade Federal do Ceará - UFC conceicaompb@yahoo.com.br

\section{Diego Saulo Alves Izequiel}

Graduado em Secretariado Executivo pela Universidade Federal do Ceará - UFC diegosaulo@hotmail.com

\section{Joelma Soares da Silva}

Mestranda Acadêmico em Administração da Universidade Estadual do Ceará UECE

joelma.soares@ufc.br 


\section{RESUMO}

O profissional de secretariado executivo vem ocupando espaço cada vez mais evidente no mercado de trabalho e na estrutura organizacional, tanto em virtude da demanda de mercado, quanto das necessidades de dinamismo na administração moderna que demonstra o crescimento da referência deste profissional. Tem buscado em seu campo de trabalho visão e atitude de atuação com excelência cumprindo o seu papel com características próprias. Este trabalho tem como objetivo geral investigar os desafios para o profissional de secretariado executivo do gênero masculino nas organizações contemporâneas. Foram definidos os seguintes objetivos específicos: analisar a inserção do gênero masculino na profissão de secretariado executivo e identificar os desafios enfrentados pelo secretário executivo do gênero masculino para o seu desenvolvimento e crescimento profissional. Para tanto, foi realizada uma pesquisa bibliográfica, seguida de uma pesquisa de campo. Trata-se de uma pesquisa qualitativa por apresentar os dados coletados e, em seguida, fazer uma análise qualitativa dos resultados com base na literatura selecionada. A pesquisa foi efetuada em organizações da esfera pública e privada, do estado do Ceará. A amostra foi representada por profissionais do gênero masculino graduados em secretariado executivo pela Universidade Federal do Ceará e que atuam na área. Após a análise dos dados concluiu-se que apesar dos obstáculos a serem superados, a tendência é que essas as oportunidades de atuação para o profissional do gênero masculino crescem, sendo necessário que todos os atores da área busquem a equidade de gêneros na profissão.

Palavras-Chave: Secretariado Executivo; Gênero Masculino; Organizações Contemporâneas. 


\section{ABSTRACT}

The Professional Executive Secretary has been occupying space increasingly evident in the labor market and organizational structure, both because of market demand, the needs of dynamism in the modern administration that demonstrates the growth of the reference to it. It has sought in his field vision and attitude of performance excellence with fulfilling its role with its own characteristics. This study aims to investigate the general challenges for the Executive Secretariat professional male in contemporary organizations. We defined the following objectives: to analyze the insertion of the male in the profession of Executive Secretary and identify the challenges faced by the Executive Secretary of the males to their development and professional growth. To this end, we performed a literature search, followed by a field survey. It is a qualitative research because data collected, and then make a qualitative analysis of results from selected literature. The survey was conducted in organizations from the public and private, state of Ceará. The sample was represented by professional male graduates in the executive secretariat at the Federal University of Ceará and working in the area. After analyzing the data it was concluded that despite the obstacles to be overcome, the tendency is that these opportunities work for the professional male grow, requiring that all actors in the field to seek gender equity in the profession.

Keywords: Executive Secretarial; Gender Male; Contemporary Organizations. 


\section{INTRODUÇÃO}

O profissional secretário executivo vem ocupando espaço cada vez mais evidente no mercado de trabalho e na estrutura organizacional, tanto em virtude da demanda de mercado, quanto das necessidades de dinamismo na administração moderna que demonstra o crescimento da referência a este profissional. Nesse contexto, estão inseridos os profissionais de secretariado executivo do gênero masculino. Nos primórdios da história a profissão de secretariado era eminentemente masculina passando a ser ocupada pelas mulheres "[...] a partir da I Guerra Mundial (1914-1918) que descortinou o mercado para a mulher" (SABINO; ROCHA, 2004, p. 8).

Com o aprofundamento da globalização da economia, das necessidades cotidianas e rotineiras no ambiente de trabalho, os mercados se deparam com a evolução da presença de mão de obra masculina na profissão de secretariado. Falar em homens na profissão de secretário executivo remete à ideia de suas competências e os laços culturais que ainda prendem a visão de algumas empresas quanto ao gênero nas atribuições da profissão. Entretanto, não é o gênero que vai dividir os fatores de produtividade na profissão e sim as suas competências no uso de suas atribuições que são comuns em ambos os gêneros. Com base nessas reflexões, este trabalho visa responder ao seguinte questionamento: que desafios são enfrentados por esse profissional para o seu desenvolvimento e crescimento nas organizações contemporâneas?

O profissional de secretariado executivo, ao deparar-se com o mercado de trabalho, passa a encontrar estereótipo - consequência da influência cultural gerada no histórico da profissão. Tal estereótipo deprecia a visão mercadológica sobre o profissional e as atribuições que the cabe, no entanto, as intensas e constantes mudanças ocasionadas pela dinâmica de mercado trazem outra vez em foco o gênero às atribuições do ofício referentes à profissão de secretário executivo. Este trabalho tem como objetivo investigar os desafios enfrentados pelo profissional de secretariado executivo do gênero masculino nas organizações contemporâneas. A principal limitação desta pesquisa ocorreu pelo fato de que a quantidade de profissionais do gênero masculino em secretariado ainda está em evolução.

Revista de Gestão e Secretariado, São Paulo, v. 2, n. 1, p.158-176, jan./jun. 2011. 


\section{OS DESAFIOS ATUAIS DO SECRETÁRIO EXECUTIVO DO GÊNERO MASCULINO}

A profissão de secretariado é exercida em sua maioria por mulheres embora se observe um crescente retorno da atuação do gênero masculino ao universo secretarial. A divisão dos gêneros dos profissionais em secretariado relativos às oportunidades decorrem de épocas remotas onde a profissão era executada predominantemente pelo gênero masculino e a indicativa é de que a criação de paradigmas enfraqueceram a presença do gênero na profissão fazendo existir a dificuldade atual da aceitação do profissional do gênero masculino na área, tal visão cultural deu-se, principalmente, durante a Segunda Guerra Mundial, conforme explica Figueiredo (1987, p. 14):

Após a Segunda Guerra Mundial, a profissão adquiriu melhores perspectivas. A catástrofe dizima milhares de bons profissionais nos campos de batalha e muitos dos que tinham conseguido regressar, estavam tão mutilados ou neuróticos, que já não podiam mais reassumir as antigas tarefas. Em contrapartida, no decorrer da Guerra, as mulheres haviam descoberto seu próprio valor, tendo servido nas fábricas de armamento, nos hospitais da frente de batalha e na substituição dos homens que partiam para luta.

Atualmente, observa-se o ressurgimento da figura do homem no exercício da profissão de secretariado para suprir as necessidades do mercado em virtude da globalização e da dinâmica administrativa. A evolução do gênero na profissão acompanha o avanço da globalização, conforme Carvalho e Grisson (1998, p. 463):

O profissional secretário participante do processo de globalização, desenvolve e aprimora diariamente suas habilidades de comunicação, além do telefone, fax, e-mail e internet. Ele é o navegador de informações, frequentemente interpretando $e$ traduzindo a multidiversidade de culturas e linguagem, sendo o elo entre a tecnologia e a realidade.

As questões relativas ao discurso sobre as diferenças entre gêneros remetem à sua evolução histórica. Para Guimarães (2004, p. 145) gênero e trabalho "[...] são dois campos temáticos que, na história das ciências sociais no Brasil, uniram-se em uma permanente fertilização recíproca, para brincar com os termos da metáfora sem pôr em questão a sua pertinência." De acordo com 
Silva, Amazonas e Vieira (2010) no século XVII, com o advento da revolução francesa e a proclamação da igualdade dos direitos, tornou-se necessário justificar a inferioridade das mulheres. Nessa época, Segundo Laqueur (1992 apud SILVA; AMAZONAS; VIEIRA, 2010, p. 152):

[...] a ciência aparece, nessa época, a serviço da cultura, com o objetivo de fundamentar a inferioridade das mulheres em sua própria natureza. Para isso foi instituído o two-sex model, um modelo que estabelece uma distinção ontológica e horizontal entre os sexos. Esse modelo surge em oposição ao modelo inspirado na filosofia neoplatônica de Galeno, em que os sexos eram concebidos hierarquicamente e regulados pelo modelo masculino. Nele não encontramos os sexos divididos segundo a sua anatomia, ao contrário, os sexos são ligados por uma anatomia comum. No onesex model, que dominou o pensamento anatômico durante dois mil anos, as mulheres eram concebidas como um homem invertido e imperfeito. Elas possuíam exatamente os mesmos órgãos que os homens, porém em lugares errados, devido à falta de calor vital. Entretanto, tal concepção não significava que homens e mulheres fossem confundidos. A diferença entre mulheres e homem era percebida, porém não era explicada através do critério da diferença sexual.

Segundo Nunes (2000 apud SILVA; AMAZONAS;VIEIRA, 2010, p. 152) as noções de homem e mulher eram de grau e não de gênero e os órgãos de reprodução eram somente:

[...] signo do lugar do corpo na ordem cultural que ultrapassa a biologia. Esse modelo dominará a reflexão sobre a diferença sexual desde a Antiguidade Clássica até o fim do século XVIII, embora as representações sobre os gêneros masculino e feminino tenham mudado, sobretudo por influência do cristianismo.

As citadas autoras salientam que esse modelo cedeu lugar, no final do século XVIII, ao modelo do dimorfismo radical, de divergência biológica, em que os registros anatômicos e fisiológicos constituíram a base para a fundamentação das diferenças entre homem e mulher. As ideias estabelecidas sobre masculino e feminino culminaram na separação entre trabalho e família. "Ascendia um sentimento novo: o de privacidade e intimidade familiar. Com a reorganização da casa, a reforma dos costumes e a exclusão dos criados, clientes e amigos, a família foi reduzida aos pais e às crianças" Áries (1981 apud SILVA; AMAZONAS; VIEIRA, 2010, p. 152).

Revista de Gestão e Secretariado, São Paulo, v. 2, n. 1, p.158-176, jan./jun. 2011. 
Silva, Amazonas e Vieira (2010) afirmam que nos séculos XIX e XX os estereótipos de mulher - esposa - mãe - dona de casa e anjo do lar modificavam-se de acordo com a camada social. O processo de industrialização de urbanização favoreceu a inserção do trabalho feminino assalariado, como operárias e professoras e salientam:

Juntamente com os movimentos sociais e as políticas de
identidade, a escola e as transformações dos grandes setores de
atividade econômica estiveram entre os principais fatores que
contribuíram para precipitar o declínio do estereótipo da esposa-
mãe-dona de casa, e promover correlativamente um
superinvestimento feminino nos papéis sociais da vida profissional.
Mais uma vez, as relações familiares e os papéis desenvolvidos por
homens e mulheres seriam modificados. A nova cultura centrada
no prazer, no lazer e na livre escolha individual desvalorizava o
modelo de vida feminina mais voltado para a família do que para si
mesma, legitimando os desejos de viver para si e desqualificando
o modelo da "perfeita dona de casa." Quanto mais crescia a oferta
de objetos, de serviços e de lazer, mais se intensificava a
exigência de aumentar os rendimentos da família, a fim de estar à
altura do ideal consumista (SILVA, AMAZONAS; VIEIRA, 2010, p,
154).

Para Araújo (2007), desde a infância depara-se com definições de masculino e feminino e adquirem-se hábitos que, por exigência da sociedade, nos identificam como homens ou mulheres e influenciam na escolha da profissão ao ingressar na carreira profissional. Segundo pesquisas de Lupton (2000 apud ARAÚJO, 2007) que tratam sobre a presença de homens em algumas áreas específicas como enfermagem, assistente social e, até mesmo secretariado, explica que não há interesse em desenvolver bibliografia que aborde as dificuldades enfrentadas por homens em profissões tidas como femininas, uma vez que o ingresso de homens em profissões tradicionalmente seguidas por mulheres é considerado um passo atrás na carreira profissional e, talvez, esta concepção explique a pequena representação masculina nessas profissões. Bolzan (2010) faz citação à reportagem "Homens no secretariado: uma questão de gênero", publicada na revista Excelência, relatando que há homens que atuam na profissão de secretariado que confessaram ter recebido sugestões de professores da sua universidade para desistirem desse curso. Outros não conseguiram se inscrever em seminários da categoria, pois era sobre o "Dia da

Revista de Gestão e Secretariado, São Paulo, v. 2, n. 1, p.158-176, jan./jun. 2011. 
Secretária" e a recepção vetou. Em outro caso, um profissional sofreu preconceito ao ser sorteado com um brinde, pois o representante do prêmio não quis entregar porque era para uma mulher e não um homem (BOLZAN, 2010). Ainda na mesma reportagem, abordam-se opiniões de profissionais homens no secretariado sobre esse preconceito, conforme relato de Bolzan (2010, p. 8):

Assessorar o chefe, redigir documentos, preparar reuniões na Secretaria Especial de Direitos Humanos da Presidência da República, entre outras atividades, é o que Hugo Nister Pessoa Teixeira, 25 anos, faz depois que se formou em Secretariado Executivo pelo Instituto de Ensino Superior de Brasília. No entanto, atuar na área traz alguns detalhes inesperados. Ele conta que as pessoas quando querem agendar com seu chefe, sempre telefonam e pergunta: "A secretária está:". Para explicar sua reação, ele diz "que é compreensível, visto que tal profissão era exercida no passado apenas por mulheres". Mas o pior mesmo é quando as pessoas demonstram claro preconceito com o fato dele ter cursado Secretariado. Boa parte das pessoas faz indagações como, por exemplo, "Esse curso não é de mulher?", reclama.

Em entrevistas com profissionais de diversas áreas que relatam situações de desconforto por estarem atuando em uma profissão atípica, atitudes como de casos de homens no secretariado, por exemplo, demonstram algumas estratégias para lidar com estas dificuldades: usar outras denominações para definirem seus papéis. Conforme Araújo (2007) isto não só não resolve o problema como ajuda a reforçar e perpetuar a imagem feminina do secretariado construída pela sociedade ao longo dos anos.

\section{DEMANDAS E OPORTUNIDADES DO MERCADO PARA O SECRETÁRIO EXECUTIVO DO GÊNERO MASCULINO}

Apesar da notória inserção do homem na área secretarial ainda prevalece a ideia de que secretariado é uma profissão feminina. Entretanto, é na necessidade de suprir as demandas de mercados diversos que o gênero masculino volta ao cenário secretarial, antes como opção, hoje em evolução. Embora o gênero feminino domine a área, o mercado é dinâmico e busca o diferencial, definindo as características que esperam do profissional. Os profissionais de secretariado do gênero masculino, assim como nas demais 
profissões, têm diante de si a complexidade dos negócios e a turbulência do ambiente empresarial, assumindo responsabilidades não apenas por tarefas, mas também por processos, o que implica lidar com uma gama de diferentes indivíduos e atender a múltiplas demandas. De acordo com Medeiros e Hernandes (2010), o profissional de secretariado deve procurar ser um elemento de cooperação e integração; considera-se capaz para desempenhar diferentes tarefas. Para Soares (2010) o secretário executivo pode atuar como gestor, assessor, consultor e empreendedor.

Dessa maneira, crescem as oportunidades de mercado para a profissão de secretariado que a cada dia exige mais conhecimento, pois quanto maior o nível de informação fundamentada de um profissional maior serão as possibilidades de atingir suas metas. A tecnologia permite um trabalho mais centrado nas funções gerenciais, onde o conhecimento é vital, logo, pode-se afirmar que a função do profissional de secretariado executivo é gerencial e estratégica. A amplitude das funções secretariais evidencia que as responsabilidades do secretário executivo podem ser atribuídas a esse profissional independente do gênero, e possibilita maiores oportunidades de atuação para o profissional de gênero masculino. Essa quebra de paradigma é consequência das mudanças culturais da sociedade no que diz respeito à questão da identidade. Tais transformações se relacionam "[...] à compreensão política de que a experiência humana não é limitada a um grupo étnico particular, a uma raça, a um gênero, a um modo de expressão da sexualidade, etc." (LOPES, 2002 apud ARAÚjO, 2007, p.19). Essa visão se reflete nas diversas áreas sociais, incluindo-se, nesse contexto, as organizações das esferas públicas e privadas, que buscam profissionais capacitados para atender às inovações organizacionais, sem distinção de gênero. Por outro lado, com relação à presença do gênero masculino na área secretarial Araújo (2007, p. 19) considera que:

Apesar das diversas pesquisas que discutem o fato de que as
identidades são dinâmicas, heterogêneas e que buscam mostrar
que gênero não é algo biologicamente determinado e sim
socialmente construído, a sociedade ainda se orienta para a
manutenção de profissões, atividades e campos de atuação
exclusivamente femininos, alimentando assim, este estereótipo.
Este fato ocorre muito fortemente no Secretariado.

Revista de Gestão e Secretariado, São Paulo, v. 2, n. 1, p.158-176, jan./jun. 2011. 
Apesar dos avanços e das crescentes oportunidades e demandas de mercado para o profissional secretário do gênero masculino, ainda há muitos desafios a serem superados para que a profissão de secretariado quebre um dos seus paradigmas mais marcantes: secretariado é uma profissão feminina. Para tanto, faz-se necessária a atuação conjunta das entidades de classe, dos profissionais e dos estudantes da área em direção à consolidação da imagem do profissional independente de gênero.

\section{MÉTOdOS E TÉCNICAS DE PESQUISA}

A pesquisa bibliográfica, segundo Marconi e Lakatos (2009, p. 44) "[...] é a que especificamente interessa a este trabalho. Trata-se de levantamento de toda a bibliografia já publicada, em forma de livros, revistas, publicações avulsas e imprensa escrita." Quanto ao nível, trata-se de um estudo exploratório descritivo, por focalizar características e levantar dados sobre opiniões e atitudes de um grupo, buscando "[...] a descrição das características de determinada população ou fenômeno ou o estabelecimento de relações entre variáveis." (GIL, 1999 , p. 44). Trata-se de uma pesquisa qualitativa visto que apresenta os dados coletados e, em seguida, faz uma análise qualitativa dos resultados com base na literatura selecionada, buscando uma relação entre as respostas dos investigados e os conhecimentos adquiridos no levantamento teórico sobre o tema. A pesquisa foi efetuada em organizações da esfera pública e privada, do estado do Ceará. A amostra foi representada por profissionais do gênero masculino graduados em secretariado executivo pela Universidade Federal do Ceará e que atuam na área. Foram localizados doze profissionais dos quais seis se disponibilizaram a participar da investigação. Para a coleta de dados foi utilizado como instrumento um questionário semiestruturado com o intuito de oferecer aos investigados a possibilidade de discorrer sobre o tema proposto.

Revista de Gestão e Secretariado, São Paulo, v. 2, n. 1, p.158-176, jan./jun. 2011. 


\section{APRESENTAÇÃO E ANÁLISE dOS RESULTADOS}

A pesquisa buscou conhecer o perfil dos investigados destacando-se que $67 \%$ dos pesquisados estão entre 21 a 30 anos de idade, sendo essa a maioria e o restante dos 33\% correspondem à idade de 31 a 40 anos; $100 \%$ graduados pela Universidade Federal do Ceará (UFC), sendo 33\% formado em 2007, 33\% em 2008, 17\% em 2009 e 17\% em 2010. Quanto ao segmento de atuação no mercado $50 \%$ entrevistados trabalham com prestação de serviços, $16 \%$ trabalham para indústria, $17 \%$ no comércio e $17 \%$ não identificaram a área. Salienta-se, ainda, que a maioria dos profissionais investigados, representada por $66 \%$, trabalham na organização por um período de um a dois anos; $17 \%$ trabalham na área secretarial de três a cinco anos e os outros $17 \%$ trabalham na área há mais de cinco anos.

Gráfico 1: Escolha da profissão

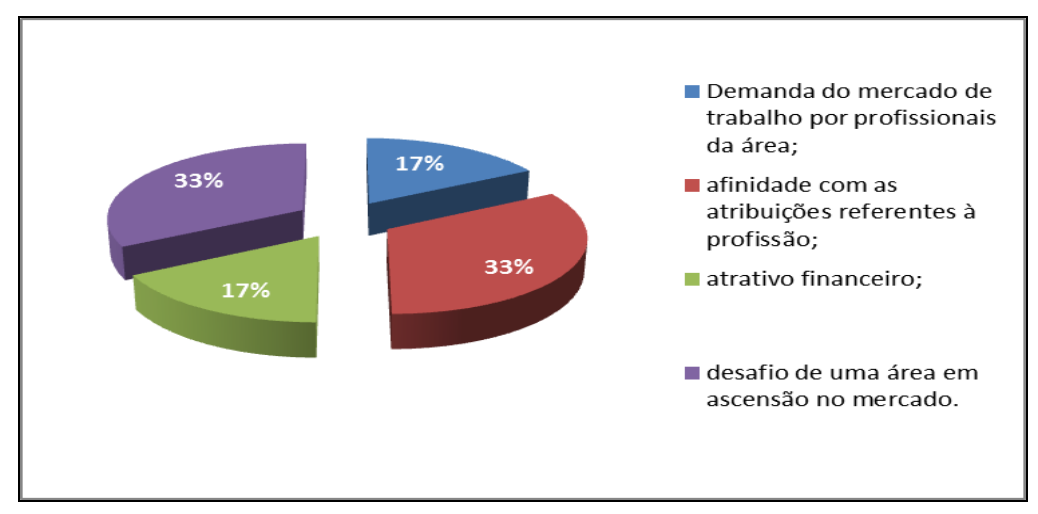

Fonte: Elaborado pelos autores.

Observa-se que a maioria dos investigados escolheu a profissão por afinidade e devido aos desafios de uma área em ascensão no mercado. Tal informação indica que o profissional de gênero masculino está sendo atraído para a área secretarial, principalmente, pela possibilidade de maiores oportunidades profissionais.

Revista de Gestão e Secretariado, São Paulo, v. 2, n. 1, p.158-176, jan./jun. 2011. 
Gráfico 2: Preconceito sobre a profissão

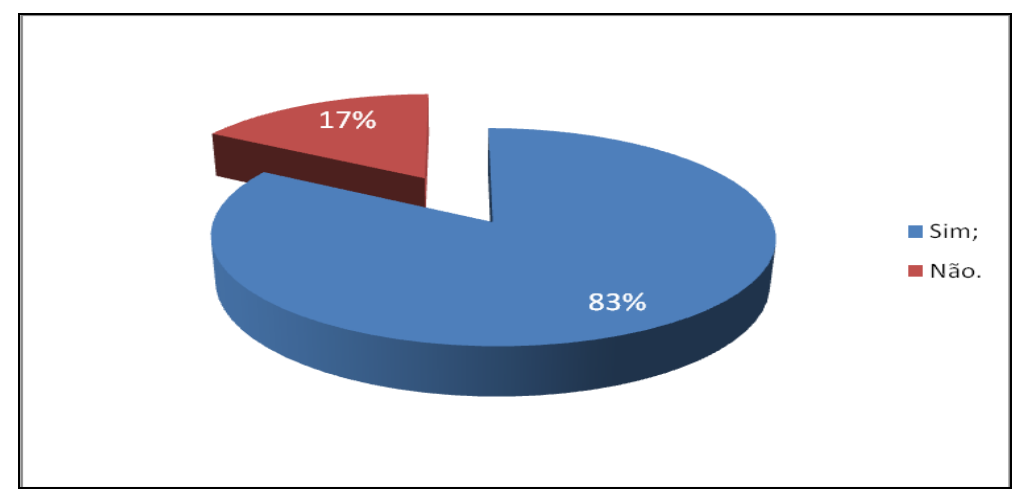

Fonte: Elaborado pelos autores.

Dentre os preconceitos relatados, a grande maioria citou a realização de entrevistas onde são avaliados, primeiramente, por serem homens. Outro tipo de preconceito refere-se ao ambiente interno de trabalho onde se é malvisto e, algumas vezes, motivo de "chacota" pela função que exerce. A minoria dos entrevistados considerou que não sofre preconceito na profissão. Observa-se que ainda existem preconceitos relacionados à atuação do gênero masculino na profissão. Sob esse aspecto, vale retomar as considerações de Araújo (2007) ao alertar que os preconceitos relacionados à atuação do secretário do gênero masculino não soluciona o problema e, sim, reforça o paradigma da imagem feminina do secretariado construída pela sociedade ao longo dos anos. As características do perfil do profissional de hoje e do futuro tendem a mudar essa visão gerada pela cultura imposta pelo estereótipo relativo à profissão no passado e que futuramente poderão ser extintas e para isso faz-se necessária a busca pela equidade dos gêneros. 
Gráfico 3: Oportunidades no mercado

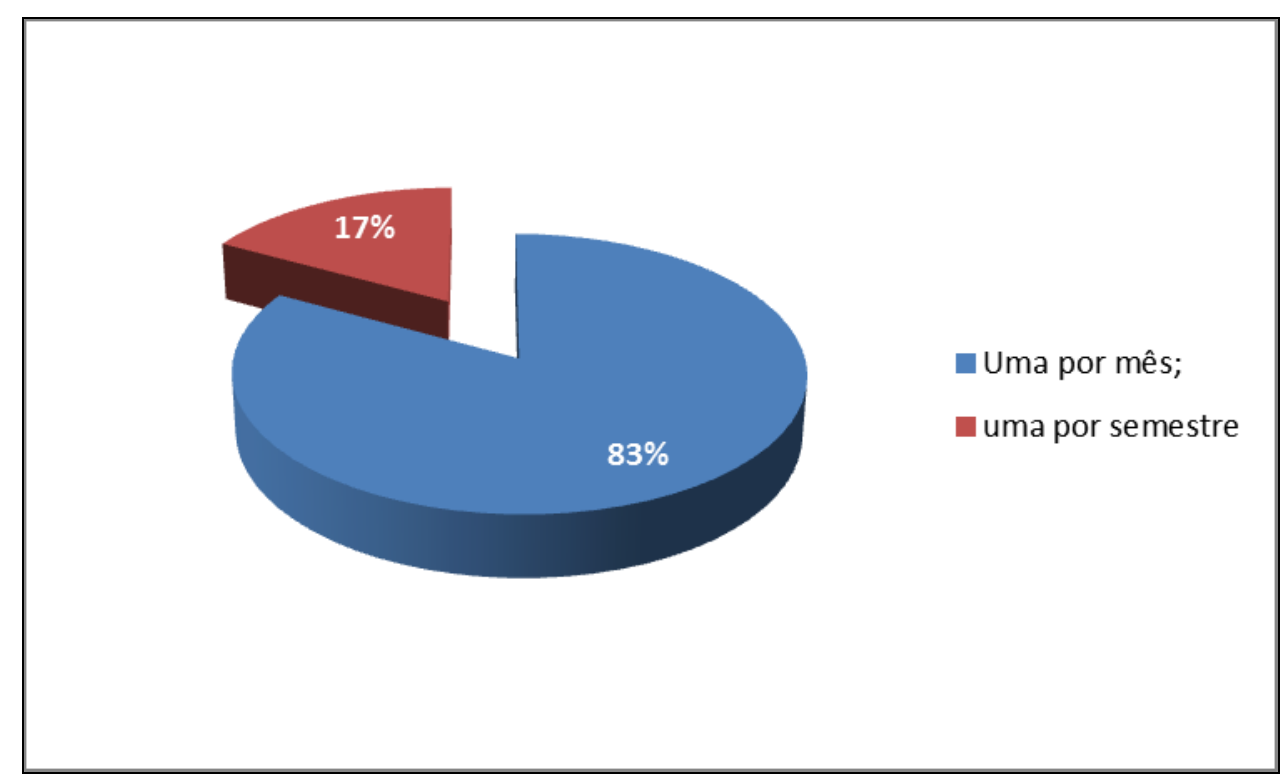

Fonte: Elaborado pelos autores.

A pergunta fez referência às demandas de mercado pelo profissional e revelou que a maioria dos entrevistados tem, pelo menos, uma oferta de emprego na área por mês. Nesse sentido, salienta-se que Medeiros e Hernandes (2010) consideram que o profissional de secretariado deve ser capaz de desempenhar uma diversidade de tarefas, o que amplia as suas oportunidades no mercado, inclusive para inserir-se na área como gestor, assessor, consultor e empreendedor (SOARES, 2010). Comparando os resultados ao gráfico anterior, pode-se notar, evidentemente, que apesar da relatada porcentagem que representa o índice dos que sofreram preconceito na profissão, o nível de oportunidades é razoavelmente alto.

Revista de Gestão e Secretariado, São Paulo, v. 2, n. 1, p.158-176, jan./jun. 2011. 
Gráfico 4: Dificuldades de inserção no mercado de trabalho.

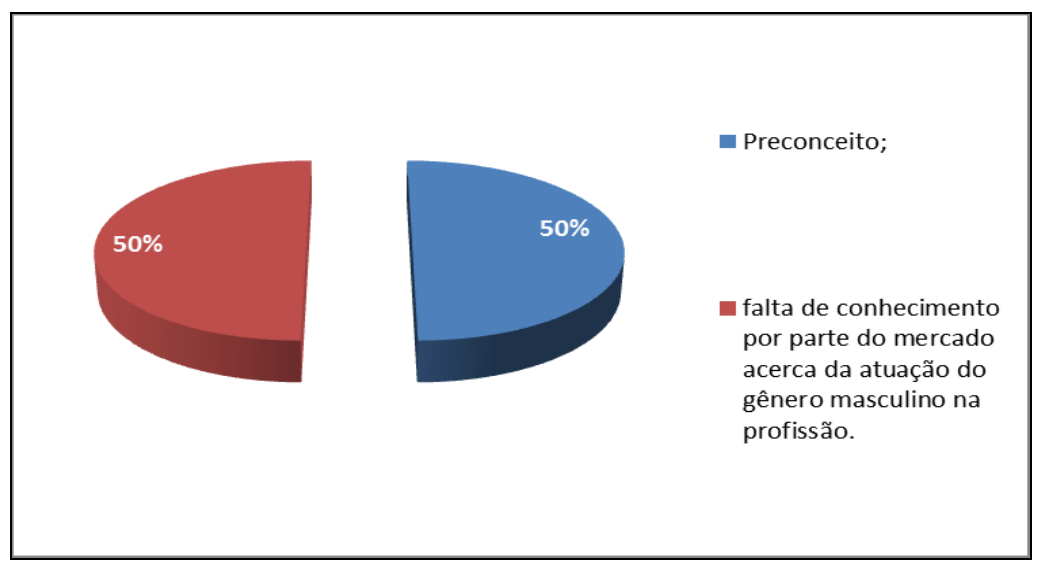

Fonte: Elaborado pelos autores.

Apesar dos resultados positivos relativos às oportunidades de trabalho para o gênero masculino apresentados anteriormente, observa-se que esse profissional ainda encontra como dificuldade para inserção na área o preconceito e a falta de conhecimento por parte do mercado acerca da sua atuação. Fundamentando-se em Araújo (2007) pode-se inferir que esse resultado denota a existência de obstáculos à inserção do profissional do gênero masculino na profissão de secretariado como consequência das distinções existentes entre masculino e feminino desde a infância, que se refletem na sociedade e na definição das profissões. Vale salientar, também, as considerações de Lupton (2000 apud ARAÚJO, 2007) ao considerar a existência de desafios para o profissional do gênero masculino em diversas profissões, tais como: enfermagem e assistente social. Dessa maneira infere-se que tal problema não é exclusividade da área secretarial. Em comparação aos gráficos 8 e 9, constata-se que o preconceito e as oportunidades profissionais são fatores intrínsecos às dificuldades de inserção do profissional no mercado de trabalho, pois metade dos investigados respondeu que a maior dificuldade emerge por conta do preconceito e a outra metade indicou ser pela falta de conhecimento por parte do mercado acerca da atuação do gênero masculino na profissão, quando o conhecimento sobre a atuação do gênero na área pode influenciar nas oportunidades.

Revista de Gestão e Secretariado, São Paulo, v. 2, n. 1, p.158-176, jan./jun. 2011. 
Gráfico 5: Desafios enfrentados pelo profissional em secretariado executivo.

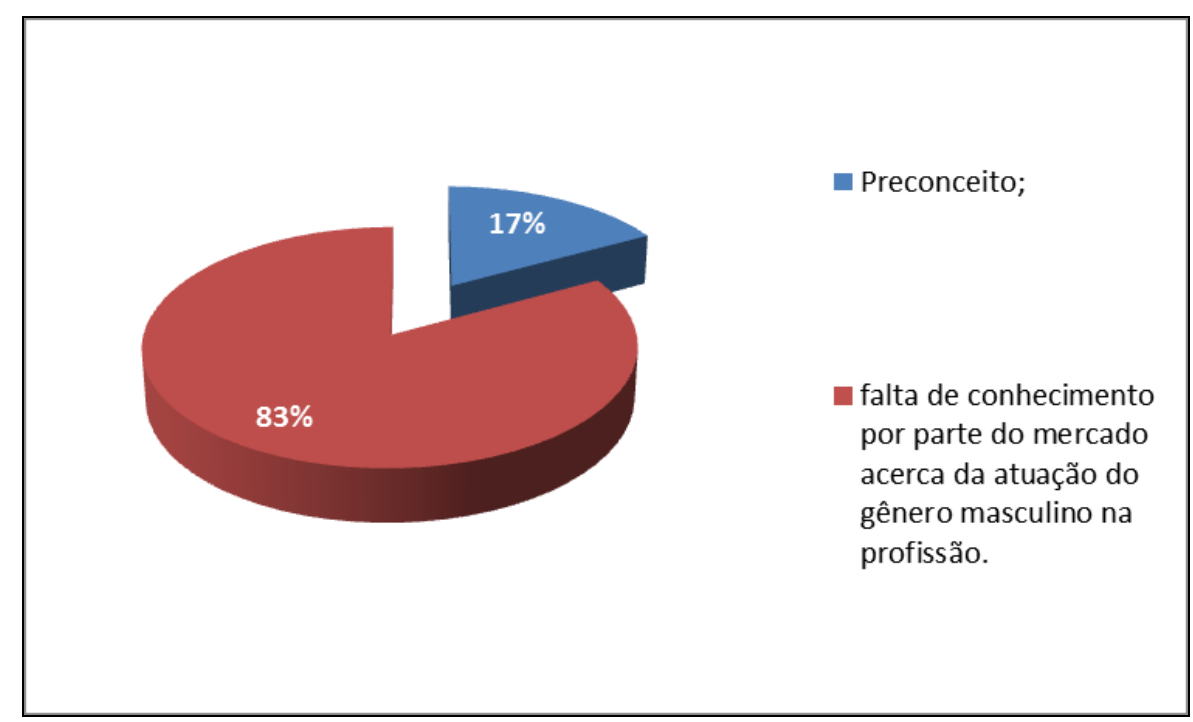

Fonte: Elaborado pelos autores.

Com relação aos desafios enfrentados pelo profissional em secretário executivo do gênero masculino para o seu desenvolvimento e crescimento profissional, a maioria dos investigados afirmou que o maior desafio enfrentado pelo profissional no exercício de trabalho é a falta de conhecimento acerca da profissão por parte do mercado. Tal resultado indica que a visão externa sobre a profissão de secretariado executivo ainda reflete a cultura imposta pela história e o desconhecimento quanto às atribuições atuais do profissional e seu perfil. Fazendo uma análise sobre os gráficos 8, 9 e 10 e os itens escolhidos, essa falta de conhecimento pode ser o gerador desse preconceito.

Gráfico 6: Avaliação das oportunidades de trabalho

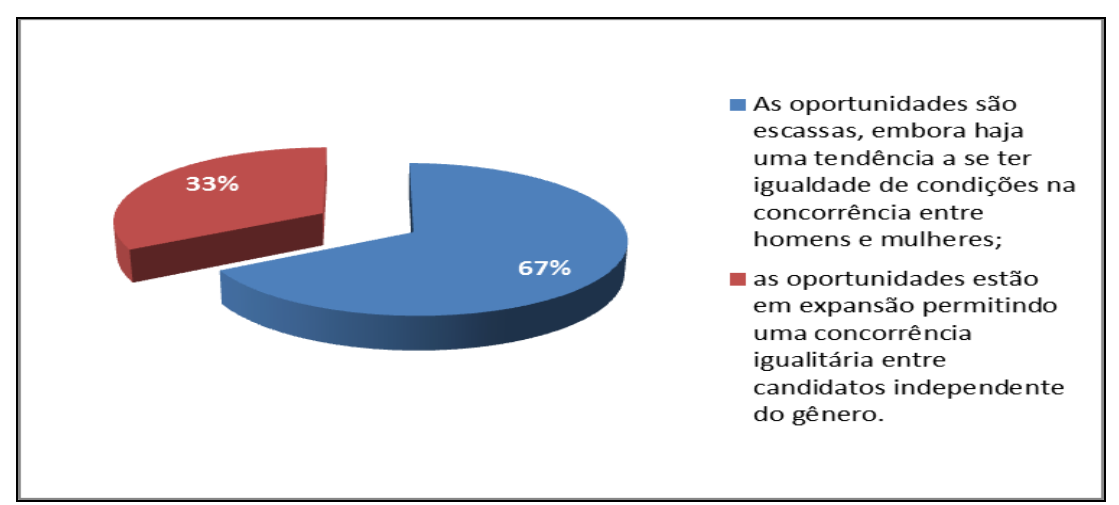

Fonte: Elaborado pelos autores.

Revista de Gestão e Secretariado, São Paulo, v. 2, n. 1, p.158-176, jan./jun. 2011. 
A partir do gráfico, visualiza-se que a maioria dos profissionais investigados afirmou que as oportunidades são escassas, embora haja uma tendência a se ter igualdade de condições na concorrência entre homens e mulheres, isso trata da equidade dos gêneros e, como prática, as comuns atribuições que não remetem de forma alguma a um foco em um dos gêneros, sendo cabíveis a ambos. Os dados coletados nas questões 11 e 12 indicam que ainda predomina a cultura construída ao longo dos tempos de que secretariado é profissão feminina, visto que a história da profissão registra a inserção da mulher na área desde a II Guerra Mundial para substituir os homens que partiram para a luta (FIGUEIREDO, 1987).

\section{CONSIDERAÇÕES FINAIS}

A partir do levantamento bibliográfico e da pesquisa de campo foi possível delinear alguns pensamentos conclusivos sobre a temática proposta. Inicialmente, observou-se que, embora timidamente, existe uma crescente inserção de profissionais do gênero masculino na área secretarial e que a evolução do perfil desse profissional tende a estar presente como agente decisivo. A figura do gênero masculino, antes de predominância na área, sofreu um afastamento, fato histórico ocorrido no fim da Segunda Grande Guerra, mas volta ao cenário devido às grandes perspectivas inerentes aos profissionais da área e às demandas de mercado. A busca pela equidade dos gêneros e pela reconquista do espaço masculino na profissão traz uma perspectiva de equilíbrio entres os gêneros na área e essa perspectiva faz perceber a dimensão das expectativas sobre o mercado.

Com relação às oportunidades no mercado de trabalho para o profissional secretário executivo do gênero masculino, foi averiguado que o seguimento de mercado que mais emprega esses profissionais refere-se ao exercício na área de serviços. Constatou-se que a demanda por profissionais da área e do gênero masculino está evoluindo, visto que os investigados apontaram para a existência de diversas oportunidades no mercado de trabalho atual para o gênero masculino na profissão.

Revista de Gestão e Secretariado, São Paulo, v. 2, n. 1, p.158-176, jan./jun. 2011. 
No que se refere aos desafios enfrentados pelo secretário executivo do gênero masculino para o seu desenvolvimento e crescimento profissional, verificou-se que, além dos desafios a serem enfrentados pelos profissionais na área, independente do gênero, esse profissional necessita de enfrentar o preconceito ainda existente na sociedade e no ambiente de trabalho contemporâneo relacionado à sua atuação. A pesquisa sinaliza a existência de uma cultura voltada para a presença de mulheres exercendo em grande maioria a profissão; essa visão ainda é muito forte e o profissional do gênero masculino lida com as suas consequências. Entretanto, o fato de identificar-se a participação de profissionais do gênero masculino com formação na área e em atuação no mercado, remete à conclusão de que, com a evolução da profissão esse paradigma deve diminuir ao longo dos tempos. Observa-se que 0 profissional do gênero masculino no exercício do secretariado executivo tende a equilibrar suas perspectivas de demanda de mercado, pois as suas responsabilidades e atribuições não fazem distinção de gênero. Ainda com relação aos desafios, foi avaliado que o profissional do gênero masculino enfrenta obstáculos na busca por um espaço no mercado de trabalho na área de secretariado executivo, indicando que, além do preconceito, existem dificuldades relativas à ausência de conhecimentos sobre a atuação masculina no mercado de trabalho.

Diante do exposto, infere-se que as demandas de mercado e as oportunidades para o profissional do gênero masculino são diversas. Apesar dos obstáculos a serem superados, a pesquisa apontou para o crescimento de oportunidades para o secretário executivo do gênero masculino, sendo necessário que todos os atores da área busquem a equidade na profissão. Embora ainda não seja tão comum identificar a atuação masculina na área secretarial, já existe uma evolução e observa-se que a sua atuação é uma realidade.

Revista de Gestão e Secretariado, São Paulo, v. 2, n. 1, p.158-176, jan./jun. 2011. 


\section{REFERÊNCIAS}

ARAÚJO, Daiana Gossmann. O espaço ocupado pelo sexo masculino no ramo de secretariado executivo. 2007. - UNB. Trabalho de Término de Curso (Bacharelado em Secretariado Executivo Bilíngüe) Centro de Ciências da Comunicação, Universidade do Vale dos Sinos/RS, 2007.

BOLZAN, Roberson Lopes. "Desafios e preconceitos enfrentados por estudantes e profissionais de secretariado executivo, destacando o preconceito pelo sexo masculino". Artigo Científico apresentado para o XVII CONSEC em 29 de maio de 2010. Disponível em: www.fenassec.com.br. Acesso em: $1^{0}$ dez. de 2010.

CARVALHO, Antônio Pires de; GRISSON, Diller Silva. Manual do secretariado executivo. São Paulo: DCL, 1998, 588p.

FIGUEIREO, Vânia. Secretariado: dicas e dogmas. Brasília: Thesaurus Ed., 1987, $160 p$.

GIL, Antonio C. Métodos e técnicas de pesquisa social. São Paulo: Atlas Ed., $1999,2007 p$.

GUIMARÃES, Nadya Araújo. Gênero e trabalho. Rev. Estud. Fem. [online]. 2004, vol.12, n. 2, pp. 145-146. ISSN 0104-026X. Disponível em: http://www.scielo.br/pdf/ref/v12n2/23965.pdf. Acesso em: 14 dez. de 2010.

MARCONI, Marina de Andrade \& LAKATOS, Eva Maria. Metodologia do trabalho científico. São Paulo: Atlas Ed., 2009, 315p.

MEDEIROS, João Bosco; HERNANDES, Sonia. Manual da Secretária: técnicas de trabalho. 12 ed. São Paulo: Atlas, 2010, 392p.

SABINO, Rosimeri Ferraz \& ROCHA, Fábio Gomes. Secretariado: do escriba ao web writer. Rio de Janeiro: Brasport Ed., 2004, 192p.

SILVA, Thálita Cavalcanti Menezes da; AMAZONAS, Maria Cristina Lopes de Almeida \& VIEIRA, Luciana Leila Fontes. "Família, trabalho, identidades de

Revista de Gestão e Secretariado, São Paulo, v. 2, n. 1, p.158-176, jan./jun. 2011. 
gênero". Psicol. estud. [online]. 2010, vol.15, n.1, pp. 151-159. ISSN 14137372. Disponível em:

http://www.scielo.br/scielo.php?script=sci pdf\&pid=S1413-

73722010000100016\&lng=en\&nrm=iso\&tlng=pt. Acesso em: 14 dez. de 2010.

SOARES, Fátima. O profissional de secretariado executivo como gestor estratégico.

Disponível

em

http://www.consultoriatarget.com.br/artigos/Oprofissional de Secretariado Exe cutivo.pdf. Acesso em 28 nov. de 2010.

Revista de Gestão e Secretariado, São Paulo, v. 2, n. 1, p.158-176, jan./jun. 2011. 